FRBSF Working Paper 2002-19

\title{
Exploring the Role of the Real Exchange Rate in Australian Monetary Policy*
}

\author{
Richard Dennis \\ Federal Reserve Bank of San Francisco
}

This version June, 2002

First version October, 2000

\begin{abstract}
An important issue in small open-economies is whether policymakers should respond to exchange rate movements when they formulate monetary policy. Micro-founded models tend to suggest that there is little to be gained from responding to exchange rate movements, and the literature has largely concluded that such a response is unnecessary, or even undesirable (Taylor, 2001). This paper examines this issue using an estimated model of the Australian economy. In constrast to micro-founded models, according to this model policymakers should allow for movements in the real exchange rate and the terms-of-trade when they set interest rates. Further, taking real exchange rate movements into account appears even more important with price level targeting than with inflation targeting.
\end{abstract}

Key words: Real exchange rate, terms-of-trade, policy.

JEL Classification: E52, E58.

\footnotetext{
*I would like to thank Adrian Pagan, Graeme Wells, and two anonymous referees for their comments on a previous draft. This paper began while I was a Research Graduate at the Reserve Bank of Australia. I would like to thank the Reserve Bank of Australia for providing their estimation output for the model examined in sections 3 and 4 . The views expressed do not necessarily reflect those of the Reserve Bank of Australia, the Federal Reserve Bank of San Francisco, or the Federal Reserve System. Address for correspondence: Economic Research Department, Mail Stop 1130, Federal Reserve Bank of San Francisco, 101 Market St, San Francisco, CA 94105, USA. Email: Richard.Dennis@sf.frb.org
} 
"Monetary policy will continue to be conducted according to the mediumterm principles contained in our inflation targeting approach. This means that the exchange rate will be taken into account, along with other variables that contribute to our inflation outlook" [Macfarlane, December 2000, p. 6]

\section{Introduction}

An important question in the monetary policy rules literature is whether optimal policy rules and the policy formulation process differ in small open economies from those in large, or closed, economies. In this regard, the exchange rate's role as a policy channel in small open economies and as a source of disturbances, spring to mind as potential differences. Obviously, in closed economy models there is no exchange rate channel into prices or aggregate demand that policymakers need to consider when setting interest rates. Studies that examine optimal policy in closed economy models often find that Taylor-type rules (Taylor, 1993), which depend only on inflation and the output gap, perform almost as well as optimal policy rules (Rudebusch and Svensson, 1999; Levin, Wieland, and Williams, 1999). The success of Taylor-type rules relative to optimal policy suggests that just two variables - inflation and the output gap - summarize much of the information that is important for setting interest rates.

One might be skeptical whether rules that perform well in closed-economy models will also perform well in small open-economy models, due to shocks entering the economy through the exchange rate and the tradable goods' sector. Ball (1999), for example, shows that responding to real exchange rate movements may be important when policymakers place a large weight on stabilizing consumer price inflation. Similarly, Svensson (2000) examines a model where responding to the exchange rate is important under consumer price inflation targeting (see Svensson, 2000, Table 2). However, overall, the literature tends to find little role for the exchange rate in policy rules. Batini, Harrison, and Millard (2001), Leitemo and Söderström (2001) and Clarida, Galí, and Gertler (2001) each examine optimal policy in small open economy models. These papers argue that by-and-large policy rules that respond to exchange rate movements generate little improvement over Taylor-type rules.

However, while these three papers reach similar conclusions regarding the exchange rate they do so for quite different reasons. Batini, et al. (2001) show that 
where policymakers respond to expected future inflation, also responding to exchange rates does very little to raise welfare. Leitemo and Söderström (2001, p. 2) establish that rules that respond to the exchange rate are "slightly more sensitive than the Taylor rule to model uncertainty"; such rules may produce less desirable outcomes if policymakers continually set policy using the wrong model. Finally, Clarida, et al. (2001) derive a small open-economy model and show that it is effectively identical to a closed-economy model. In their model the exchange rate is irrelevant, aside from that it makes consumption more sensitive to interest rate movements. From a policy perspective, the exchange rate's main role in these models is to provide a channel through which monetary policy can effect the economy; it provides little, or no, independent information that is useful for forecasting or stabilizing the economy. In this vein, Taylor (2001, p. 266) offers the conclusion that “... either [...] there are small performance improvements from reacting to the exchange rate or that such reactions can make performance worse."

These models imply that central banks in small open-economies should not respond to appreciations or depreciations in their currencies. They should only respond to movements in the exchange rate to the extent that the exchange rate itself is a "fundamental." Conversely, central banks that do respond to exchange rate movements may, through their actions, transmit unnecessary volatility into inflation and the real economy. However, the models in Batini, et al. (2001), Leitemo and Söderström (2001), and Clarida, et al. (2001) are micro-founded and calibrated, not estimated. Moreover, these models are not tailored to reflect the characteristics of the Australian economy, which may limit their aplicability to the Australian context.

The Reserve Bank of Australia's views on the exchange rate's role for setting policy are clear

"As for why things are not fully summed up in the interest rate itself, the reason is clearly that the exchange rate is not just mechanically related to the interest rate instrument; it is subject to shocks. These shocks mean that the exchange rate conveys information in its own right, and will have an impact on the economy apart from what comes through its response to shifts in the monetary policy instrument. Hence, it is worth having that information available when considering monetary policy." [Stevens, August 1998, p. 37, italics in original] 
and subsequently

"I am certainly not suggesting that we should ignore the exchange rate; far from it. It is a key relative price in the economy. Policy-makers must, and do, form views about movements in the exchange rate as part of the policy process. But oversimplification is not a virtue. There is no alternative to the hard grind of careful and detailed analysis, taking into account all the available information. When we want to assess the impact of monetary policy on the economy, we have to look at how the instrument is set, at the elements of the various transmission linkages, and assess external and other independent influences, including exchange rates." [Stevens, August 1998, p. 43]

These excerpts, together with that preceding this Introduction, suggest that the exchange rate is an important variable that influences the Bank's thinking about monetary policy. Explicit references to movements in the exchange rate and its independent information content underscore the exchange rate's role in helping the Bank predict and stabilize inflation and aggregate demand; the exchange rate is not viewed simply as a channel through which monetary policy operates (c.f. Clarida, et al., 2001; Taylor, 2001).

Small-scale empirical models of the Australian economy do tend to find a relationship between the cash rate and the exchange rate. For example, Dungey and Pagan (2000) develop an eleven equation SVAR that includes Australian macroeconomic aggregates and their dependence on the rest of the world. Within their SVAR there is an equation for the overnight cash rate that explicitly responds to real exchange rate movements. Similarly, Brischetto and Voss (1999) estimate a seven equation SVAR in which (in their preferred specification) the Reserve Bank of Australia (RBA) responds to US interest rates, oil prices, a narrow measure of nominal money balances, and the nominal exchange rate. In their specification, not only does Australian monetary policy respond to the exchange rate, but there is also contemporaneous interaction between the cash rate and the exchange rate.

In this paper we explore the exchange rate's role in Australian monetary policy. We examine a small-scale macroeconomic model for Australia (de Brouwer and O'Regan, 1997) that has been developed, and is used for forecasting and optimal control exercises, within the RBA (Stevens, 2001). Using the de Brouwer and O'Regan 
(1997) model we solve for optimal policy rules assuming that the RBA implements an inflation targeting regime (to be made more precise later). We show that the model's structure implies that the exchange rate and the terms-of-trade both enter the optimal policy rule. To investigate the importance of these two variables for economic outcomes we use (optimized) simple rules to demonstrate what happens when one or both of these variables is omitted from the rule.

The second contribution of this paper is that it formally compares inflation targeting with price level targeting in Australia. We show that responding to real exchange rate movements is even more important for price level targeting than it is for inflation targeting. Finally, while Svensson (1999b) argues that price level targeting can generate less volatility in both output and inflation than inflation targeting, we find that this is not the case in the de Brouwer and O'Regan model. However, a regime that merges inflation and price level targeting can lower the variance of inflation, generate much greater price level predictability, with little effect on output's volatility.

The structure of this paper is as follows. In the following section we analyze the theoretical models developed in Galí and Monacelli (2000) and McCallum and Nelson $(1999,2001)$. Using these models we show that whether policymakers should respond to exchange rate movements depends on how imported goods are modeled. In section 3 we focus on a model that has been developed within the RBA and that is routinely used during forecast rounds (Stevens, 2001). We present the model, describe its properties, and relate its characteristics back to Galí and Monacelli (2000) and McCallum and Nelson (2001). In section 4 we use a set of optimized simple rules to show that in this model it is optimal for policymakers to respond to real exchange rate movements as well as terms-of-trade movements. In fact, ignoring these variables leads to noticeably inferior outcomes. As part of our analysis we investigate "forwardlooking" rules and price level targeting regimes. Section 5 concludes.

\section{Two Micro-Founded Sticky-Price Small Open-Economy Models}

In this section we describe the properties of two sticky-price open-economy macroeconomic models. The first is derived in Galí and Monacelli (2000); the second in McCallum and Nelson (2001). Both models are natural extensions to closed economy sticky price models, following in the tradition of the "new open economy macro" (Obstfeld and Rogoff, 1996). The reasons for analyzing these models are threefold. 
First, these models illustrate the exchange rate's role as a policy channel and highlight situations where the exchange rate appropriately enters the policy rule. As we establish below, whether policymakers should respond to exchange rate movements hinges on whether imports are treated as consumption goods or as intermediate inputs. Second, the properties of these theoretical models assist in understanding the results that follow in sections 3 and 4 . Third, it is of interest to compare these optimization-based models and to contrast their properties with the time series characteristics of Australian macroeconomic data.

Each model is written in terms of log-linearized equations and thus all variables represent percent (or percentage point in the case of interest rates and inflation) deviations from steady-state values.

\subsection{Galí and Monacelli (2000)}

In Galí and Monacelli (GM) there are representative households and representative firms. Households consume a Dixit-Stiglitz consumption aggregate, $c_{t}$, that consists of goods produced at home, $c_{h t}$, and goods imported from the rest of the world, $c_{f t}$. Aggregate consumption obeys the standard consumption Euler equation while the share of imported goods in the consumption aggregate depends on the elasticity of substitution between home and foreign goods and the real exchange rate, $q_{t}$ (the number of foreign goods that exchange for one domestic good). ${ }^{1}$

Firms are monopolistically competitive and operate in a Calvo (1983) style pricing environment. The home production technology is log-linear in labor and a technology shock, $z_{t}$. The solution to the firm's profit maximization problem leads to a Phillips curve in which domestic goods inflation, $\pi_{t}$, depends on expected future inflation and marginal costs, $m c_{t}$. In turn, marginal costs are a function of the terms-of-trade, $s_{t}$ (price of foreign good in domestic currency relative to price of the domestically produced good), foreign output, $y_{t}^{*}$, and the technology shock, $z_{t}$.

Costless arbitrage between home and foreign financial assets motivates uncovered interest parity. GM assume that the law of one price holds and consequently the real exchange rate and the terms-of-trade are perfectly correlated. There is only one domestic shock, the technology shock, which impacts marginal costs through its

\footnotetext{
${ }^{1} \mathrm{~A}$ decrease in $q_{t}$ represents a real depreciation. For consistency with section 3 , in the presentation here we have changed the definition of the real exchange rate relative to Galí and Monocelli's (2000) original presentation. A similar alteration has been made to the McCallum and Nelson (2001) model.
} 
effect on labor's productivity. The final equation defines (log deviations in) output, $y_{t}$, through the national-accounts identity, where imports and exports have been substituted for their determinants.

Conditional upon the foreign variables, $y_{t}^{*}, i_{t}^{*}$, and $\pi_{t}^{*}$, the complete specification is

$$
\begin{aligned}
c_{t} & =(1-\alpha) c_{h t}+\alpha c_{f t} \\
c_{t} & =E_{t} c_{t+1}-\frac{1}{\sigma}\left(i_{t}-E_{t} \pi_{t+1}^{c}\right) \\
c_{f t} & =c_{t}+\eta q_{t} \\
q_{t} & =(\alpha-1) s_{t} \\
\pi_{t}^{c} & =\pi_{t}+\alpha\left(s_{t}-s_{t-1}\right) \\
\pi_{t} & =\beta E_{t} \pi_{t+1}+\lambda m c_{t} \\
m c_{t} & =\left(1+\frac{\phi \omega}{\sigma}\right) s_{t}+(\sigma+\phi) y_{t}^{*}-(1+\phi) z_{t} \\
s_{t} & =E_{t} s_{t+1}+i_{t}^{*}-E_{t} \pi_{t+1}^{*}-\left(i_{t}-E_{t} \pi_{t+1}\right) \\
z_{t} & =\rho z_{t-1}+\epsilon_{z t} \\
y_{t} & =(1-\alpha) c_{h t}+\alpha c_{t}^{*}+\alpha \eta(2-\alpha) s_{t},
\end{aligned}
$$

where $E_{t}$ represents the mathematical expectations operator conditional upon information available in period $t$. All else constant, a higher nominal interest rate induces consumers to defer consumption, lowering current period demand for the domestically produced good. A higher nominal interest rate also makes domestic assets more attractive to investors, which appreciates the terms-of-trade and the real exchange rate and directs consumers to substitute away from domestically produced goods and toward foreign goods. The appreciation in the terms-of-trade lowers firms' marginal costs placing downward pressure on the inflation rate of the domestically produced good. Lower inflation in the domestic good coupled with the appreciation in the real exchange rate leads to lower consumer price inflation. The final avenue through which monetary policy operates is through expectations; anticipations of tighter policy in the future place downward pressure on today's inflation rate.

Several aspects of this model are notable. First, the real exchange rate and the terms-of-trade are perfectly correlated. One could use this relationship to eliminate either variable from the system. Second, with a flexible domestic inflation target the 
policy objective function is (Svensson, 1997)

$$
\text { Loss }=(1-\beta) \sum_{j=0}^{\infty} \beta^{j}\left[\mu\left(\pi_{t+j}\right)^{2}+(1-\mu) y_{t+j}^{2}\right], 0 \leq \mu \leq 1,
$$

and the system's state vector is $\left[\begin{array}{llll}z_{t-1} & y_{t}^{*} & i_{t}^{*} & \varepsilon_{z t}\end{array}\right]$. Alternatively, if the policy regime embodies flexible consumer price inflation targeting, then the objective function is

$$
\text { Loss }=(1-\beta) \sum_{j=0}^{\infty} \beta^{j}\left[\mu\left(\pi_{t+j}^{c}\right)^{2}+(1-\mu) y_{t+j}^{2}\right], 0 \leq \mu \leq 1
$$

and here the system's state vector becomes $\left[\begin{array}{lllll}q_{t-1} & z_{t-1} & y_{t}^{*} & i_{t}^{*} & \varepsilon_{z t}\end{array}\right]$, which includes the real exchange rate because of its influence on the importables component in consumer price inflation. ${ }^{2}$ Thus, there is some role for the real exchange rate in the policy rule, but policymakers should only respond to the real exchange rate if they are targeting consumer price inflation. ${ }^{3}$ Third, manipulating equations (1) (5) yields the following "forward-looking IS curve"

$$
c_{h t}=E_{t} c_{h t+1}-\left(\frac{1+\alpha(\eta \sigma-1)}{\sigma}\right)\left(i_{t}-E_{t} \pi_{t+1}\right) .
$$

Provided $\eta \sigma>1$, a condition that will hold in the model's calibration, this forward-looking IS curve only differs from its closed economy counterpart in that the economy's openness leads to $c_{h t}$ responding more to interest rate movements. ${ }^{4}$

\subsection{McCallum and Nelson (2001)}

McCallum and Nelson (2001) (MN) derive a micro-founded small open-economy model with a different flavor to Galí and Monacelli (2000). The critical difference between their model and GM is that imports do not enter consumption, but are used entirely as intermediate inputs (see also McCallum and Nelson, 1999). Because

\footnotetext{
${ }^{2}$ Under domestic inflation targeting what matters for policy transmission is expected future consumer price inflation, $E_{t} \pi_{t+1}^{c}$, which is given by the constraint $E_{t} \pi_{t+1}^{c}=E_{t} \pi_{t+1}+\alpha\left(E_{t} s_{t+1}-s_{t}\right)$. Under consumer price inflation targeting the appropriate constraint is $\pi_{t}^{c}=\pi_{t}+\alpha\left(s_{t}-s_{t-1}\right)$. Consequently, $s_{t-1}$ enters the state vector under consumer price inflation targeting, but not under domestic inflation targeting.

${ }^{3}$ It is important to appreciate that responding to real exchange rate movements is very different from targeting the exchange rate. The set-up described above is one in which the central bank targets consumer price inflation and the output gap, but the decision rule that implements the optimal policy contains the lagged real exchange rate because it is part of the state vector.

${ }^{4}$ In effect, the economy's openness makes the IS curve steeper; a familiar result from static openeconomy IS-LM analysis (Parkin and Bade, 1990, Chapter 15).
} 
imports do not enter consumption there is no distinction between domestic inflation and consumer price inflation, and no direct exchange rate channel into consumer prices. Furthermore, in MN all goods in the consumption aggregate have sticky prices whereas in GM only domestically produced goods are sticky and import prices are fully flexible. We will not present the model's derivation, but the notation is consistent with GM, and many behavioral equations are easily recognizable. Their model is

$$
\begin{aligned}
c_{t} & =E_{t} c_{t+1}-b_{1}\left(i_{t}-E_{t} \pi_{t+1}^{c}\right)+v_{t} \\
y_{t} & =\omega_{1} c_{t}+\omega_{2} g_{t}+\omega_{3} x_{t}-\omega_{4} i m_{t} \\
i m_{t} & =y_{t}+\sigma q_{t} \\
x_{t} & =y_{t}^{*}-\sigma^{*} q_{t} \\
\bar{y}_{t} & =\left(\frac{\alpha \sigma}{1-\alpha}\right) q_{t}+z_{t} \\
\pi_{t}^{c} & =\beta E_{t} \pi_{t+1}^{c}+\lambda\left(y_{t}-\bar{y}_{t}\right) \\
q_{t} & =E_{t} q_{t+1}+i_{t}^{*}-E_{t} \pi_{t+1}^{*}-\left(i_{t}-E_{t} \pi_{t+1}^{c}\right)+\xi_{t} \\
z_{t} & =\rho_{z} z_{t-1}+\varepsilon_{z t} \\
v_{t} & =\rho_{v} v_{t-1}+\varepsilon_{v t} \\
\xi_{t} & =\rho_{\xi} \xi_{t-1}+\varepsilon_{\xi t} .
\end{aligned}
$$

Exports, imports, and government expenditure are denoted $x_{t}, i m_{t}$, and $g_{t}$, respectively; potential output is denoted $\bar{y}_{t}$. There are three shocks in the model all of which follow $\mathrm{AR}(1)$ processes. For this macroeconomic model, the system's state vector is $\left[\begin{array}{lllllllll}z_{t-1} & v_{t-1} & \xi_{t-1} & \varepsilon_{z t} & \varepsilon_{v t} & \varepsilon_{\xi t} & i_{t}^{*} & p_{t}^{*} & y_{t}^{*}\end{array}\right]$, which does not include the real exchange rate. In this model the exchange rate simply provides a transmission mechanism through which interest rate movements affect output and inflation. Provided policymakers respond to the fundamentals, the exchange rate contains no additional information that is relevant for forecasting, or for setting policy. That the exchange rate does not enter the policy rule is consistent with Clarida, et al. (2001), and reinforces Taylor's (2001) conclusion that it is often unnecessary and inappropriate for policymakers to respond to exchange rate movements. 


\subsection{Some Model Properties ${ }^{5}$}

For both models we solve for the optimal policy rule and the recursive equilibrium law of motion under discretion, assuming $\mu=0.5$ in equation (6). ${ }^{6}$ We then use the solution to construct the autocorrelation functions for the real exchange rate, consumer price inflation, and the output gap, and compare these across models and with the corresponding autocorrelation functions generated from Australian data. ${ }^{7}$ Results are shown in Table 1.

\begin{tabular}{ccccccccc}
\hline \hline Table 1 & \multicolumn{7}{c}{ Model Properties versus Australian Data } \\
\hline \hline \multicolumn{8}{c}{ Lag length } \\
\hline Panel 1 & 1 & 2 & 3 & 4 & 5 & 6 & 7 & 8 \\
\hline$y_{t}$ & 0.84 & 0.63 & 0.41 & 0.20 & 0.06 & -0.07 & -0.19 & -0.26 \\
$q_{t}$ & 0.85 & 0.70 & 0.56 & 0.39 & 0.26 & 0.15 & 0.04 & -0.03 \\
$\pi_{t}^{c}$ & 0.56 & 0.54 & 0.48 & 0.46 & 0.37 & 0.30 & 0.22 & 0.21 \\
\hline Panel 2 & \multicolumn{10}{c}{ AC function for Galí and Monacelli model } \\
\hline$y_{t}$ & 0.91 & 0.82 & 0.74 & 0.67 & 0.60 & 0.54 & 0.49 & 0.44 \\
$q_{t}$ & 0.91 & 0.82 & 0.74 & 0.67 & 0.60 & 0.54 & 0.49 & 0.44 \\
$\pi_{t}^{c}$ & 0.91 & 0.82 & 0.73 & 0.66 & 0.59 & 0.54 & 0.48 & 0.44 \\
\hline Panel 3 & AC function for McCallum and Nelson model \\
\hline$y_{t}$ & 0.95 & 0.90 & 0.85 & 0.81 & 0.77 & 0.73 & 0.70 & 0.66 \\
$q_{t}$ & 0.49 & 0.26 & 0.15 & 0.10 & 0.07 & 0.06 & 0.05 & 0.05 \\
$\pi_{t}^{c}$ & 0.95 & 0.90 & 0.85 & 0.81 & 0.77 & 0.73 & 0.70 & 0.66 \\
\hline \hline
\end{tabular}

Panel 1 presents the autocorrelation functions for Australia's output gap, real exchange rate, and consumer price inflation. GM's model (Panel 2) does not do too badly at capturing the autocorrelation function for Australia's real exchange rate at short lags. As the lag length gets longer, however, it becomes increasingly inconsistent with the data. Moreover, the model implies that the autocorrelation functions for the output gap, the real exchange rate, and consumer price inflation are almost identical, which is not true of Australian data. Varying the weights

\footnotetext{
${ }^{5}$ The parameter values used for these simulations are taken from Galí and Monacelli (2000) and McCallum and Nelson (2001). These parameters are reported in Appendix A.

${ }^{6}$ Several solution procedures are available to solve for discretionary equilibria in forward-looking rational expectations models (See Oudiz and Sachs, 1985; Currie and Levine, 1985, 1993; Backus and Driffill, 1986). Numerical algorithms are described in Backus and Driffill (1986), Söderlind (1999) and Dennis (2001). In this paper Dennis' algorithms were used. Variables in the rest of the world have been conditioned upon and normalized to zero.

${ }^{7}$ The Australian data used to construct panel 1 of Table 2 come from the IFS database. The mnemonics are 19399B.RZF, 193..RECZF, and 19364...ZF for real GDP, the real exchange rate, and consumer prices, respectively. The output gap was constructed using the HP filter (lambda $=1600$ ) over 1959Q3 - 2001Q2. The sample autocorrelation functions use data spanning 1984Q1 - $2001 \mathrm{Q} 2$.
} 
in the policy objective function has very little effect on the model's autocorrelation function, whose properties are largely determined by the persistence parameter $\rho$ in the technology shock process. It is worth noting that the only endogenous persistence that arises in GM comes from the fact that the lagged real exchange rate helps predict future consumer price inflation. Thus, under consumer price inflation targeting the real exchange rate should enter the optimal policy rule. ${ }^{8}$

Turning to Panel 3, it is clear that MN's model generates too much persistence in inflation and the output gap, particularly at longer lags, and too little persistence in the real exchange rate. MN's model contains no endogenous persistence, so the properties of these autocorrelation functions are determined entirely by the parameters in the shock processes.

\section{A Small-Scale Data-Consistent Model of the Australian Economy}

In the previous section we used two micro-founded sticky-price small open-economy models to illustrate the role the exchange rate plays in policy formulation. Using Galí and Monacelli's model we showed that the exchange rate channel made consumption of the domestically produced good more sensitive to interest rate movements. We further showed that whether policymakers should respond to exchange rate movements depends on whether consumer price inflation or domestic inflation enters the objective function. In McCallum and Nelson's model we showed that policymakers should not respond to real exchange rate movements.

By way of contrast, in the Introduction we noted that estimated SVAR models of the Australian economy tend to find that the RBA responds to exchange rate movements when it sets policy. However, it is not clear from those SVAR models whether this response occurs because the exchange rate helps predict future inflation, á la Galí and Monacelli (2000), or whether it is due to some alternative mechanism. Moreover, the mere presence of the exchange rate in these estimated rules does not quantify how important the response is. In other words, it is not clear whether responding to the exchange rate is an essential aspect of good policy making, or whether exchange rate movements can be over-looked with relatively minor consequences.

To investigate this issue we employ a small-scale macroeconometric model that

\footnotetext{
${ }^{8}$ Alternatively, because the real exchange rate and the terms-of-trade are perfectly correlated, policymakers could respond to terms-of-trade movements and achieve identical economic outcomes.
} 
was developed and is maintained within the RBA. This model is described in de Brouwer and O'Regan (1997). The primary advantage to using this model is that it is employed for optimal control simulations and for forecasting within the Bank (Stevens, 2001), which directly establishes its relevance for Australian monetary policy. Moreover, the model is empirically based, widely documented, and relatively easy to solve and analyze. An additional feature is that the model contains equations for both the real exchange rate and the terms-of-trade, which allows us to consider the importance of both variables.

\subsection{The Model}

The de Brouwer and O'Regan (1997) model consists of six behavioral equations and three identities. ${ }^{9} \quad$ The optimization problem facing policymakers will be linearquadratic. Consequently, all equation intercepts have been omitted (they do not affect the system's dynamics or stability properties) and all variables denote percent (or percentage point) deviations from steady-state values. The model is

$$
\begin{aligned}
y_{t}= & 0.75 y_{t-1}-0.1 q_{t-1}+0.05 s_{t-1}-0.22\left(i_{t-1}-4 \pi_{t-1}^{c}\right)+\varepsilon_{y t} \\
\pi_{t}^{c}= & -0.16\left(p_{t-1}^{c}-0.69 l c_{t-1}-0.31 p_{t-1}^{i}\right)+0.15 \Delta l c_{t-1}+0.16 y_{t-1} \\
& -0.18 \Delta l c_{t-2}+0.02 \pi_{t-2}^{i}+\epsilon_{\pi t} \\
q_{t}= & 1.09 \Delta s_{t}+0.63 q_{t-1}+0.25 s_{t-1}+0.66\left(i_{t-1}-4 \pi_{t-1}^{c}\right)+\epsilon_{q t} \\
\Delta l c_{t}= & -0.1\left(l c_{t-1}-p_{t-1}^{c}\right)+0.2 y_{t-1}+0.42 \pi_{t-1}^{c}+0.58 \pi_{t-2}^{c}+\varepsilon_{c t} \\
\pi_{t}^{i}= & -0.34\left(p_{t-1}^{i}-p_{t-1}^{c}\right)+0.58 \pi_{t}^{c}-0.58 q_{t}+0.19 \pi_{t-1}^{c}+0.05 q_{t-1} \\
& -0.21 \pi_{t-1}^{i}+0.19 q_{t-2}+\epsilon_{\pi^{i} t} \\
s_{t}= & 1.68 s_{t-1}-0.81 s_{t-2}+\epsilon_{s t} \\
p_{t}^{c}= & p_{t-1}^{c}+\pi_{t}^{c} \\
l c_{t}= & l c_{t-1}+\Delta l c_{t}
\end{aligned}
$$

\footnotetext{
${ }^{9}$ Two minor adjustments have been made to the specification described in de Brouwer and O'Regan (1997). The first is that the lag structure with which interest rates effect activity has been simplified, with an average over six lags reduced to a single lag. The second is that an error correction term (with a small speed of adjustment coefficient) has been added to the unit labor costs equation so that real unit labor costs have a well defined steady-state. In the IS curve the coefficients on the real exchange rate and the terms-of-trade have been imposed with their values taken from Shuetrim and Thompson (1999). Remaining parameters in the model were estimated within the Bank during a routine re-estimation of the model, and the results provided to the author. This re-estimation uses the dataset described in de Brouwer and O'Regan (1997), but updated to 1998Q2. The exact sample sizes and estimation periods differs across equations. See Beechey, et al. (2000) for a recent description and discussion of the Bank's model.
} 


$$
p_{t}^{i}=p_{t-1}^{i}+\pi_{t}^{i}
$$

were the notation used is consistent with section 2 and foreign variables have been conditioned upon and normalized to zero. ${ }^{10}$ Unlike the models in the previous section, which contain highly autoregressive shocks and very little in the way of endogenous dynamics, this model has many lagged variables and the six shocks are assumed to be white noise.

The theory underlying this model is looser than for the models in the previous section, but, broadly speaking, equation dynamics are motivated on generalized rigidities and adjustment costs while steady-state relationships are consistent with neoclassical growth theory. Equation (7) is an IS curve in which the output gap responds to an ex post real interest rate, but also to open economy variables such as the real exchange rate and the terms-of-trade. Consumer price inflation, equation (8), is modeled using the mark-up theory of pricing. The mark-up is proportional to the (lagged) output gap (see de Brouwer and Ericsson, 1997). The unit labor costs, $l c_{t}$, equation, equation (10), posits that workers negotiate higher wages as productivity and consumer price inflation rise, and that real wages rise above productivity when output is above potential (so that $y_{t-1}$ is positive). The import price, $p_{t}^{i}$, inflation equation (equation (11)) is an error correction equation that is based on the law-of-one-price holding in the long-run. World prices and world inflation have been eliminated from the import price equation using the definition for the real exchange rate: $q_{t}=p_{t}^{c}+e_{t}-p_{t}^{*}$, where $e_{t}$ is the effective nominal exchange rate. ${ }^{11}$ The real exchange rate, equation (9), responds to arbitrage possibilities, the differential between domestic and world real interest rates, and to structural determinants, the terms-oftrade. Finally, the terms-of-trade, as a variable determined in world markets, does not respond to domestic factors, but is instead modeled as an $\operatorname{AR}(2)$ process.

\subsection{Model Properties}

Three equations (equations (8), (10), and (11)) contain error correction terms. These error correction terms imply that in steady state consumer prices, unit labor costs, and import prices are related according to $p_{t}^{c}=p_{t}^{i}=l c_{t}$. As we now show, the fact

\footnotetext{
${ }^{10}$ Aside from the nominal interest rate all variables are expressed as log-levels; growth rates $\left(\Delta l c_{t}\right.$, $\left.\pi_{t}^{c}, \pi_{t}^{i}\right)$ are calculated as the time diferences of the log-level variables.

${ }^{11}$ The nominal exchange rate, $e_{t}$, represents the number of "foreign dollars" that one Australian dollar can buy. An increase in $e_{t}$ represents an appreciation of the Australian dollar.
} 
that any two of the error correction terms implies the third has repercussions for the system's steady state.

At this stage the model is incomplete because it lacks a policy rule. The monetary policy instrument in the model, and in the Australian economy, is the overnight cash rate. Accordingly, we close the system with the (Taylor-type) rule: $i_{t}=2.5 \pi_{t}^{c}+1.5 y_{t}$. Using "hats" to denote steady-state values, the system can be written in matrix-vector form as $\mathbf{A} \widehat{\mathbf{x}}=\mathbf{b}$ with

$$
\begin{aligned}
& {\left[\begin{array}{cccccccccc}
0.25 & -0.88 & 0 & 0.1 & 0 & 0 & 0 & 0 & -0.05 & 0.22 \\
-0.16 & 1 & 0.16 & 0 & 0.03 & -0.11 & -0.02 & -0.05 & 0 & 0 \\
0 & -1 & 0 & 0 & 0 & 0 & 0 & 0 & 0 & 0
\end{array}\right.} \\
& \mathbf{A}=\left[\begin{array}{cccccccccc}
0 & -1 & 0 & 0 & 0 & 0 & 0 & 0 & 0 & 0 \\
0 & 2.64 & 0 & 0.37 & 0 & 0 & 0 & 0 & -0.25 & -0.66 \\
-0.2 & -1 & -0.1 & 0 & 1 & 0.1 & 0 & 0 & 0 & 0 \\
0 & 0 & 0 & 0 & -1 & 0 & 0 & 0 & 0 & 0 \\
0 & -0.77 & -0.34 & 0.34 & 0 & 0 & 1.21 & 0.34 & 0 & 0 \\
0 & 0 & 0 & 0 & 0 & 0 & -1 & 0 & 0 & 0 \\
0 & 0 & 0 & 0 & 0 & 0 & 0 & 0 & 0.13 & 0 \\
-1.5 & -2.5 & 0 & 0 & 0 & 0 & 0 & 0 & 0 & 1
\end{array}\right], \\
& \widehat{\mathbf{x}}=\left[\begin{array}{c}
\widehat{y} \\
\widehat{\pi}^{c} \\
\widehat{p}^{c} \\
\widehat{q} \\
\Delta \widehat{l c} \\
\widehat{l} c \\
\widehat{\pi}^{i} \\
\widehat{p}^{i} \\
\widehat{s} \\
\widehat{i}
\end{array}\right] \text {, and } \mathbf{b}=\left[\begin{array}{l}
0 \\
0 \\
0 \\
0 \\
0 \\
0 \\
0 \\
0 \\
0 \\
0
\end{array}\right] \text {. }
\end{aligned}
$$

Applying standard eigenvalue methods to the coefficient matrix, $\mathbf{A}$, reveals that it is non-invertable with a single eigenvalue equaling zero. The economic implication of this singularity is that the system does not have a unique steady state. Nonuniqueness occurs because with "sticky prices" and a Taylor-type rule inflation is stabilized, but the price level follows a unit-root. Cointegrating relationships between the consumer price level, unit labor costs, and import prices mean that these variables are all driven by a single common trend.

This non-uniqueness is not surprising; it is a standard feature of inflation targeting regimes in sticky-price models and would be apparent in GM or MN if we had simply added the identity $p_{t}^{c}=p_{t-1}^{c}+\pi_{t}^{c}$. We did not include this identity in those models because, with inflation targeting, it was redundant. In the de Brouwer and O'Regan model the unit root is more obvious because several equations are in error correction 
form. If the policy rule were to respond to the price level instead of inflation, then this price level "indeterminacy" would be eliminated (see section 4.3). As it stands all elements in $\widehat{x}$ are unique, except for $\widehat{p}^{c}, \widehat{l c}$, and $\widehat{p}^{i}$. However, the relative prices $l c-p^{c}$ and $p^{i}-p^{c}$ are unique in steady-state, due to the cointegrating vectors. The steady state value for $y_{t}, \widehat{y}$, is zero. Because the mark-up in the mark-up pricing equation is proportional to the output gap this implies that the level of the mark-up is zero in steady state.

To demonstrate the system's dynamic properties, we apply a positive 1 per cent shock to the IS curve, assuming policy is set using the Taylor-type rule above. The responses of output, consumer prices, consumer price inflation, and the real exchange rate are shown in Figure 1.

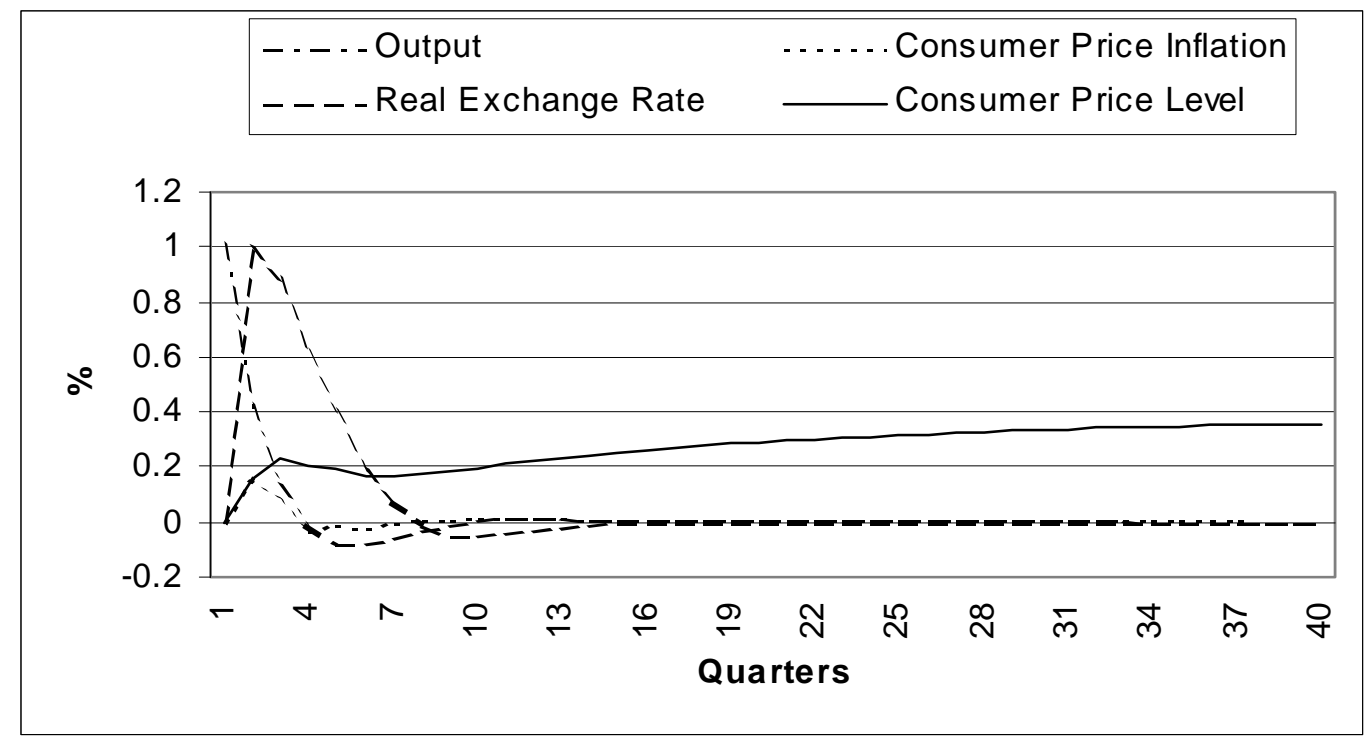

Figure 1: Responses to 1 per cent demand shock

In response to a 1 per cent demand shock, output immediately rises the full percentage point. Subsequently, consumer price inflation begins to rise in response to excess demand. Higher inflation and a positive output gap lead to a monetary policy tightening and the higher interest rate generates capital inflows and an exchange rate appreciation. Although the shock has temporary effects on the output gap, consumer price inflation, and the real exchange rate, consumer prices are left permanently higher.

It is of interest to compare how the de Brouwer and O'Regan model treats imports in relation to GM and MN. If the de Brouwer and O'Regan model treats imports as 
consumption goods then we can expect the real exchange rate to enter the optimal policy rule. Alternatively, if imports are treated as intermediate inputs, then MN's model suggests that the exchange rate will not enter the optimal policy rule. Casual inspection of the mark-up pricing equation suggests that imports are being treated as intermediate inputs. The long-run of this mark-up pricing equation has $p_{t}^{c}=$ $0.69 l c_{t}+0.31 p_{t}^{i}$. If the mark-up price equation modeled firms' output prices, $p_{t}$, then this interpretation would have more merit. However, the equation models consumer prices not firm's output prices.

Now, consider an environment in which labor is the only factor input in a (CobbDouglas) production function and in which firms are monopolistically competitive. From profit maximization, firms' output-prices will be a mark-up over marginal costs and equal to average costs through the zero-profit condition. In this production environment, average costs equal average unit labor costs, i.e., $p_{t}=l c_{t}$. Taking the time difference of the long-run consumer price relationship gives $\pi_{t}^{c}=0.69 \Delta l c_{t}+$ $0.31 \pi_{t}^{i}$, which can now be written as $\pi_{t}^{c}=0.69 \pi_{t}+0.31 \pi_{t}^{i}$. Turning to the GM model, there the consumer price equation is $\pi_{t}^{c}=\pi_{t}+\alpha\left(s_{t}-s_{t-1}\right)$. Employing GM's definition of the terms-of-trade, this expression for consumer price inflation can be written as $\pi_{t}^{c}=\pi_{t}+\alpha\left(p_{t}^{i}-p_{t}-p_{t-1}^{i}+p_{t-1}\right)$, or $\pi_{t}^{c}=(1-\alpha) \pi_{t}+\alpha \pi_{t}^{i}$. The similarities between the consumer price inflation equation and the steady-state consumer price inflation equation in de Brouwer and O'Regan are immediate. Thus, in steady-state at least, the consumer price equation in de Brouwer and O'Regan is consistent with imports being consumption goods, not intermediate inputs. Consequently, we can expect the real exchange rate to enter the optimal policy rule in the de Brouwer and O'Regan model. ${ }^{12}$

\section{Optimal Simple Rules}

In this section we examine how economic outcomes and policy performance are affected by whether the central bank responds to the real exchange rate and/or the terms-of-trade. The approach we take is to consider simple rules that encompass the four possibilities, and to then choose feedback parameters for these rules to optimize the central bank's forward-looking policy objective function. The next step is

\footnotetext{
${ }^{12}$ From a modeling perspective, the critical difference between the consumer price inflation specifications in de Brouwer and O'Regan (1997), GM, and MN is the following. In MN consumer price inflation responds to the level of the exchange rate (through the output gap) whereas in de Brouwer and O'Regan and GM consumer price inflation responds to the change in the exchange rate.
} 
to examine how each rule's performance depends on the objective function's precise parameterization. The performances of these optimal simple rules are shown relative to the optimal policy rule, which is solved using dynamic programming ${ }^{13}$ (Sargent, 1987). To solve for optimal simple rules we evaluate the objective function for some arbitrary coefficients and then (numerically) minimize the objective function with respect to these coefficients.

\subsection{Inflation Targeting}

To investigate the importance of the real exchange rate and the terms-of-trade for policy, we calculate the value of the minimized loss (objective) function for four optimized simple rules relative to the optimal policy rule. We model the RBA as a flexible consumer price inflation targeter ${ }^{14}$ with the following loss function (Svensson, $1997)^{15}$

$$
\text { Loss }=(1-\beta) \sum_{j=0}^{\infty} \beta^{j}\left[\mu\left(4 \times \pi_{t+j}^{c}\right)^{2}+(1-\mu) y_{t+j}^{2}\right], 0 \leq \mu \leq 1 .
$$

To solve for the optimal policy rule we express the model in state-space form and apply dynamic programming. In the de Brouwer and O'Regan model the state variables are $\left[\begin{array}{llllllllllllll}y_{t} & \pi_{t}^{c} & \pi_{t-1}^{c} & q_{t} & q_{t-1} & \Delta l c_{t} & \Delta l c_{t-1} & \pi_{t}^{i} & \pi_{t-1}^{i} & s_{t} & s_{t-1} & p_{t}^{c} & l c_{t} & p_{t}^{i}\end{array}\right]$. Optimal policy rules are linear functions of all 14 state variables. ${ }^{16}$ It may appear disquieting that the optimal rule is a function of current period $y_{t}, \pi_{t}^{c}, q_{t}, \Delta l c_{t}$, and $s_{t}$ - particularly $q_{t}$-, given the potential for rapid asset flows between countries. However, the model's structure asserts that these contemporaneous variables are not

\footnotetext{
${ }^{13}$ One may expect the non-stationarity of some variables to cause problems when solving for optimal rules. However, because there are cointegrating relationships between the non-stationary variables, and because it is these stationary linear combinations that enter the system's state vector, and not the non-stationary variables themselves, we can still employ dynamic programming solution methods.

${ }^{14}$ The Reserve Bank of Australia is a self described inflation targeter (MacFarlane, 2000; Stevens, 1999). Following Svensson (1997, 1999a) inflation targeting is invariably modeled using an intertemporal loss function with quadratic penalties on inflation and the output gap. In this spirit, equation (13) is intended to be a positive, rather than a normative, statement about Australian monetary policy.

${ }^{15}$ This objective function depends on the discount factor, $\beta$. In the limit as $\beta \rightarrow 1$ this loss function converges to Loss $=\mu \operatorname{Var}\left(4 \times \pi_{t}^{c}\right)+(1-\mu) \operatorname{Var}\left(y_{t}\right)$, see Dennis (2001). All results in this section are based on the loss function evaluated in this limiting case. Despite appearances, the loss function is still forward-looking. It is just that $\pi_{t}^{c}$ and $y_{t}$ are stationary and ergodic in the solution, which allows the intertemporal loss function to be evaluated using ensemble variances. We multiply $\pi_{t}^{c}$ by 4 to annualize the measure of consumer price inflation targeted in the objective function.

${ }^{16}$ The feedback coefficients applied to $p_{t}^{c}, l c_{t}$, and $p_{t}^{i}$ will be such that the cointegrating vectors are preserved and thus the right hand side of this rule will consist of stationary variables and stationary combinations of non-stationary variables.
} 
significantly influenced by the current interest rate setting and hence that the policymaker can condition upon them when setting policy. This is not something that we have assumed; it is a feature inherent to the model. ${ }^{17}$

Given this state vector, we solve for the optimal feedback coefficients (the $\phi$ 's) in the following four simple rules

$$
\begin{aligned}
& \text { (Rule 1) } \quad i_{t}=\phi_{1} \pi_{t}^{c}+\phi_{2} y_{t}+\phi_{3} q_{t}+\phi_{4} s_{t} \\
& \text { (Rule 2) } \quad i_{t}=\phi_{1} \pi_{t}^{c}+\phi_{2} y_{t}+\phi_{3} q_{t} \\
& \text { (Rule 3) } \quad i_{t}=\phi_{1} \pi_{t}^{c}+\phi_{2} y_{t}+\phi_{4} s_{t} \\
& \text { (Rule 4) } i_{t}=\phi_{1} \pi_{t}^{c}+\phi_{2} y_{t} \text {. }
\end{aligned}
$$

Rule 4 is, of course, a Taylor-type rule. We then evaluate the loss function for each (optimized) simple rule and divide by the loss for the optimal policy rule, thereby generating a relative loss measure. Figure 2 shows how this relative loss measure varies as $\mu$ changes.

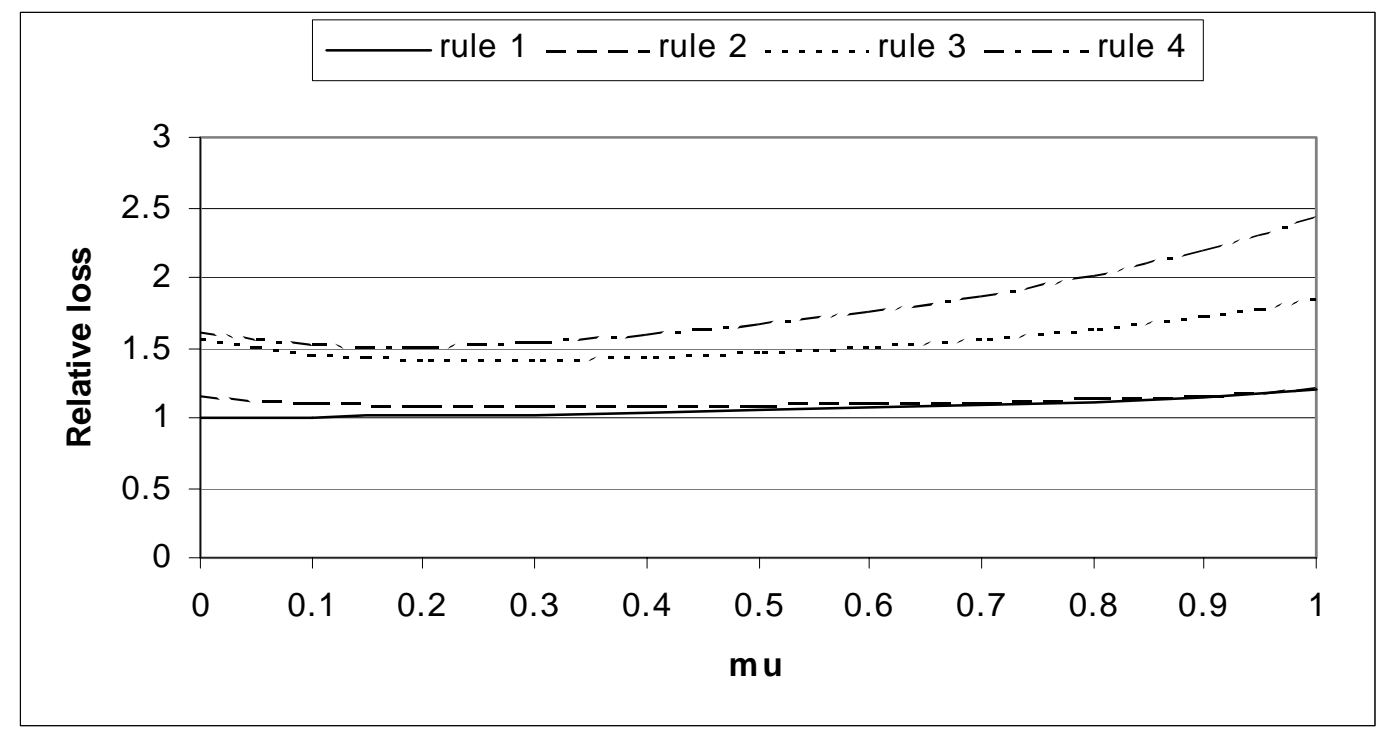

Figure 2: Relative loss for inflation targeting rules

\footnotetext{
${ }^{17}$ We note in passing that the presence of the contemporaneous real exchange rate in the rule facilitates interpreting optimal policy in terms of a Monetary Conditions Index (MCI). To construct a nominal MCI the real exchange rate term would be factored into its three constituent parts and the nominal exchange rate term taken to the left hand side of the rule to be combined with the nominal interest rate. By solving for inflation expectations as a function of the state vector one could similarly construct the implied real MCI rule. Whether the MCI rule is written in real or nominal terms, optimal policy requires keeping actual monetary conditions (the LHS of the rule) equal to desired monetary conditions (the RHS of the rule). It is worth noting, however, that the Reserve Bank of Australia is adamantly opposed to giving MCI's any formal role in monetary policy (Stevens, 1998).
} 
Certain features of Figure 2 occur through construction and it is worthwhile mentioning these before turning to the results themselves. With optimized coefficients, policy rules that encompass simpler structures will necessarily perform better, or at least no worse. Because of this effect, Rule 1 will perform at least as well as the other three rules, and Rules 2 and 3 will perform at least as well as Rule 4 . In looking at Figure 2, then, we are particularly interested in how Rules 2 and 3 perform relative to the optimal policy, and hence to each other, and in the extent to which Rule 4 (a Taylor-type rule) is inferior to the other rules.

Rule 1 performs almost as well as the optimal policy rule when $\mu$ is small, but its performance deteriorates as $\mu$ rises. Not responding to the terms-of-trade (Rule 2) leads to a modest increase in loss, but not responding to the real exchange rate produces a much bigger increase in loss - for all values of $\mu$. Thus, not responding to the real exchange rate represents a decidedly inefficient use of information. The amount by which relative loss rises is increasing in $\mu$. Accordingly, the more policymakers focus on stabilizing consumer price inflation the more important it is for them to account for real exchange rate movements. That the real exchange rate's importance is increasing in $\mu$ is also a feature of Ball (1999) and GM, but not of MN. Finally, notice that employing a Taylor-type rule, and not responding to either the terms-of-trade or the real exchange rate leads to loss more than doubling for $\mu \geq 0.80$, and for loss deteriorating at least $50 \%$ for all $0 \leq \mu \leq 1$.

These findings reinforce our analysis of GM in section 2. There we showed that monetary policy should respond to movements in the real exchange rate if imports were consumption goods and if policymakers target consumer price inflation. In this section we have used an empirical model of the Australian economy to show that this channel is important in practice. One difference between these results and those in section 2 is that in the de Brouwer and O'Regan model we find that there is some limited value in responding to the terms-of-trade in addition to the real exchange rate. In GM the real exchange rate and the terms-of-trade were perfectly correlated, so policymakers only needed to consider one of these variables.

\subsection{Forward-Looking Rules}

In the previous section monetary policy was forward-looking with this "forwardlookingness" reflected in the central bank's intertemporal policy objective function. An alternative that some authors prefer is to build monetary policy's forward-looking 
dimension directly into the policy rule (Batini and Haldane, 1999; Batini, et al., 2001; de Brouwer and O'Regan, 1997). Usually this means that expected future inflation enters the rule, although occasionally expectations of future output gaps are also used (de Brouwer and O'Regan, 1997). One advantage that forward-looking rules have is that they often closely approximate the optimal policy rule, but do so in terms of only a few variables.

Batini and Haldane (1999) and Batini, et al. (2001) study small open-economy models and show that rules containing expectations of future inflation are "lag encompassing" and "output encompassing." In essence, lag encompassing means that the information contained in lagged variables is useful for policy only to the extent that it helps predicts future inflation; output encompassing means that once expected future inflation, at a carefully chosen horizon, enters the rule there is no additional need to also include the output gap. In this terminology, the issue examined in this section is whether forward-looking rules are also real exchange rate encompassing and terms-of-trade encompassing.

de Brouwer and O'Regan (1997) examine the efficiency of forward-looking inflation targeting rules. They cast their analysis in terms of Taylor-type rules and show that monetary policy is most efficient when two-quarter-ahead expectations of inflation and the output gap enter the rule. Whereas de Brouwer and O'Regan make the Taylor rule forward-looking in both inflation and the output gap, the rules we examine only contain expectations of future inflation. Instead of putting expectations of future output gaps in the rule, we focus on whether rules containing expected future inflation summarize the information contained in the terms-of-trade and the real exchange rate. By construction, these forward-looking rules cannot perform better than the optimal policy rule, which is constructed using dynamic programming (and which efficiently uses all relevant information).

The rules that we examine are

$$
\begin{aligned}
& \text { (Rule 5) } \quad i_{t}=\phi_{1} E_{t} \pi_{t+2}^{c}+\phi_{2} y_{t}+\phi_{3} q_{t}+\phi_{4} s_{t} \\
& \text { (Rule 6) } \quad i_{t}=\phi_{1} E_{t} \pi_{t+2}^{c}+\phi_{2} y_{t}+\phi_{3} q_{t} \\
& \text { (Rule 7) } \quad i_{t}=\phi_{1} E_{t} \pi_{t+2}^{c}+\phi_{2} y_{t}+\phi_{4} s_{t} \\
& \text { (Rule 8) } \quad i_{t}=\phi_{1} E_{t} \pi_{t+2}^{c}+\phi_{2} y_{t} \\
& \text { (Rule 9) } \quad i_{t}=\phi_{1} E_{t} \pi_{t+2}^{c} \text {. }
\end{aligned}
$$


Each of these forward-looking rules contain expected inflation two quarters ahead. ${ }^{18}$ It is natural to focus on rules containing two quarter ahead inflation expectations because it takes two quarters for interest rate movements to impact consumer price inflation (i.e., the control lag into consumer price inflation is two quarters). Rules 5 - 8 are the forward-looking analogues to Rules 1 - 4. We include Rule 9 to investigate whether these forward-looking rules are output encompassing. Using equation (13) as the policy objective function, the feedback parameters in these five forward-looking rules are solved for by evaluating the objective function as a function of proposed parameters and then (numerically) minimizing the objective function with respect to these parameters.

Figure 3 is the analogue to Figure 2, but in terms of the five forward-looking rules. The loss for each of the five rules is shown relative to the loss under the optimal policy rule. Actually, Figure 3 only shows results for Rules 8 and 9. Results for Rules 5 7 are visually indistinguishable from those for Rule 8 .

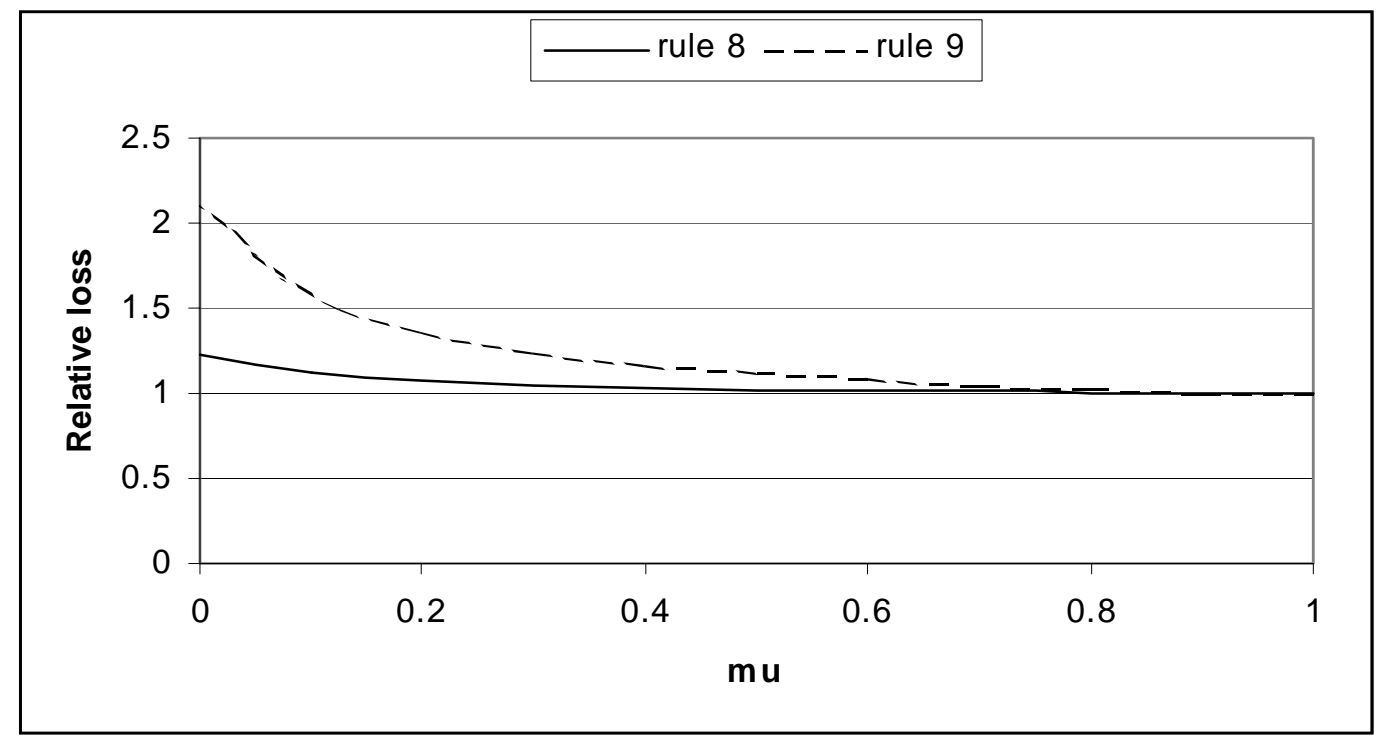

Figure 3: Relative loss for forward-looking rules

Three things are apparent from Figure 3. First, the inferiority of Rule 9 relative to Rule 8 reveals that with two-quarter-ahead expectations the forward-looking rule is not output encompassing for low values of $\mu .{ }^{19}$ This result stands in contrast

\footnotetext{
${ }^{18}$ Experimenting with forward-looking rules in which the lead on inflation was only one quarter we found that such rules perform poorly relative to the optimal rule. Our use of two-quarter ahead inflation expectations is consistent with de Brouwer and O'Regan (1997).

${ }^{19}$ Of course we could see whether placing three-quarter ahead, or four-quarter ahead, etc, inflation
} 
to Batini, et al. (2001), who considered only $\mu=0.5$. For $\mu=0.5$ our result is in broad agreement with theirs. Second, Rules $5-8$ perform very well relative to the optimal rule for most values of $\mu$, some differences are apparent when $\mu$ is small and policymakers favor output stabilization. Third, once inflation expectations and the output gap enter the rule only trivial performance improvements accrue to also including the real exchange rate and/or the terms-of-trade. The latter result is striking given that the message of section 4.1 was that not responding to movements in the real exchange rate or in the terms-of-trade produces inferior outcomes.

Reconciling the results above with those in section 4.1 is not difficult; it simply requires looking at how inflation expectations are formed as a function of the state vector. In fact a criticism of forward-looking rules is that they are not decision rules. Forward-looking rules contain variables whose values are determined simultaneously with the policy instrument (in this case expected future inflation) and consequently such rules describe how endogenous variables are related along the equilibrium path. But, forward-looking rules do not describe how policy is set to achieve this equilibrium path. For the latter we require a decision rule, which is an expression relating the policy instrument to the state vector (Hansen and Sargent, 1980). Written in terms of the 14 state variables, the optimal rule, Rule 5 , and Rule 8 , all with $\mu=0.5$, are

$$
\begin{aligned}
& \text { (Optimal) } i_{t}=3.00 y_{t}+5.32 \pi_{t}^{c}+1.18 \pi_{t-1}^{c}-0.52 q_{t}+0.09 q_{t-1}-1.70 \Delta l c_{t} \\
& +0.21 \Delta l c_{t-1}+0.07 \pi_{t}^{i}-0.02 \pi_{t-1}^{i}-0.04 s_{t}+0.21 s_{t-1} \\
& -0.90 p_{t}^{c}+0.67 l c_{t}+0.23 p_{t}^{i} \\
& \text { (Rule 5) } i_{t}=2.97 y_{t}+3.60 \pi_{t}^{c}+1.62 \pi_{t-1}^{c}-0.45 q_{t}+0.10 q_{t-1}-2.14 \Delta l c_{t} \\
& +0.25 \Delta l c_{t-1}+0.10 \pi_{t}^{i}-0.03 \pi_{t-1}^{i}-0.15 s_{t}+0.27 s_{t-1} \\
& -1.03 p_{t}^{c}+0.75 l c_{c}+0.28 p_{t}^{i} \\
& \text { (Rule 8) } i_{t}=3.17 y_{t}+3.87 \pi_{t}^{c}+1.74 \pi_{t-1}^{c}-0.37 q_{t}+0.11 q_{t-1}-2.31 \Delta l c_{t} \\
& +0.27 \Delta l c_{t-1}+0.11 \pi_{t}^{i}-0.03 \pi_{t-1}^{i}-0.24 s_{t}+0.29 s_{t-1} \\
& -1.11 p_{t}^{c}+0.81 l c_{c}+0.30 p_{t}^{i} \text {. }
\end{aligned}
$$

These three rules have several notable features. First, there is relatively little

expectations in the rule could produce a rule that is output encompassing, but this is not the main focus of the paper. 
variation in the feedback coefficients across each of the rules. The greatest differences are in the coefficients applied to the consumer price inflation terms, but here the sum of the two coefficients is similar across rules. Second, Rule 5 and Rule 8 exhibit clear responses to both the real exchange rate and the terms-of-trade. Third, relative to the optimal rule, Rule 5 and Rule 8 respond less to real exchange rate movements and more to terms-of-trade movements. Finally, in each of the rules the sum of the feedback coefficients on the levels variables $\left(p_{t}^{c}, l c_{t}\right.$, and $\left.p_{t}^{i}\right)$ equal zero. This final result holds due to the cointegrating vectors linking these three variables.

\subsection{Price Level Targeting}

In this section we move away from inflation targeting and turn to consider price level targeting. Our objectives are twofold. First, we wish to investigate the importance of responding to the terms-of-trade and the real exchange rate in a price level targeting environment. Second, we wish to compare the merits of price level targeting relative to inflation targeting.

On the second issue, several authors have argued that price level targeting offers important advantages over inflation targeting. In particular, price level targeting allows agents to better anticipate the path of future prices, which facilitates better decision making. Svensson (1999b) theorizes that once policymakers have a reputation for maintaining low and stable inflation, price level targeting can be introduced without generating the higher output and inflation volatility that is commonly found in simulated price level targeting regimes. Moreover, Svensson points out that with a price level target unusually low inflation creates the expectation of higher future inflation, which can lower (ex ante) real interest rates even if nominal interest rates are constrained at zero. King (1999) shows that the key difference between inflation targeting and price level targeting is really just the horizon over which inflation is targeted. If policymakers aim for a 2 per cent average inflation rate over $h$ years, then, as $h$ tends to $\infty$, this translates into stabilizing the price level about a 2 per cent trend. Thus it is really just the horizon $h$ that separates price level targeting from inflation targeting.

When it adopted inflation targeting the RBA described its policy objective as ensuring that inflation was $2 \%-3 \%$ "on average, over the course of the cycle" (Stevens, 1999, pp48). ${ }^{20}$ Harding and Pagan (2002, Table 1) show that the Australian business

\footnotetext{
${ }^{20}$ Reference to the length of the business cycle has subsequently been replaced with an appeal to
} 
cycle has an average duration of (approximately) 6 years. ${ }^{21}$ Viewed this way, the RBA's inflation targeting approach may well embody aspects of price level targeting. Later we construct a hybrid price level/inflation targeting regime and show that it has several attractive properties.

A price level targeting regime is taken to be one where the policymaker sets policy to minimize ${ }^{22}$

$$
\text { Loss }=(1-\beta) \sum_{j=0}^{\infty} \beta^{j}\left[\delta\left(p_{t+j}^{c}\right)^{2}+(1-\delta) y_{t+j}^{2}\right], 0 \leq \delta \leq 1 .
$$

The system's state vector does not change and, as with inflation targeting, we can solve for optimal policy rules using dynamic programming. However, whereas the sum of the feedback coefficients on $p_{t}^{c}, l c_{t}$, and $p_{t}^{i}$ necessarily equaled zero under inflation targeting, they are not so related under price level targeting. Consequently, when subject to control, $p_{t}^{c}, l c_{t}$, and $p_{t}^{i}$ are stationary variables with unique steadystate values. In equation (14) the implied target for the consumer price level is zero (variables are in logs). The steady-state linear relationships between $p_{t}^{c}, l c_{t}$, and $p_{t}^{i}$ then imply that each (logged) variable equals zero in steady-state. ${ }^{23}$

Following the approach in section 4.1 we compare the performance of four (optimal) simple rules relative to the optimal policy rule. The rules considered differ from those in section 4.1 , however, in that they have policymakers responding to consumer prices rather than consumer price inflation

$$
\begin{aligned}
& \text { (Rule 10) } \quad i_{t}=\phi_{1} p_{t}^{c}+\phi_{2} y_{t}+\phi_{3} q_{t}+\phi_{4} s_{t} \\
& \text { (Rule 11) } \quad i_{t}=\phi_{1} p_{t}^{c}+\phi_{2} y_{t}+\phi_{3} q_{t} \\
& \text { (Rule 12) } \quad i_{t}=\phi_{1} p_{t}^{c}+\phi_{2} y_{t}+\phi_{4} s_{t} \\
& \text { (Rule 13) } i_{t}=\phi_{1} p_{t}^{c}+\phi_{2} y_{t} \text {. }
\end{aligned}
$$

For a given value of $\delta$, we optimize over the feedback parameters in these rules and evaluate the loss for each optimal simple rule relative to that for the optimal policy rule. Results are shown in Figure 4.

\footnotetext{
the "medium-term" (Macfarlane, 2000, pp6; Stevens, 1999, pp46).

${ }^{21}$ Harding and Pagan's dataset covers the post-war period 1959.Q1 - 1997.Q1.

${ }^{22}$ Following sections 4.1 and 4.2 , we focus on the limiting case where $\beta \longrightarrow 1$. In which case this policy objective function converges to a weighted average of the unconditional variances of the output gap and the consumer price level. See footnote 15.

${ }^{23}$ In terms of section 4.2 , placing non-zero coefficients on one (or more) of $p_{t}^{c}, l c_{t}$, and $p_{t}^{i}$ in the policy rule leads to a non-singular A matrix. This implies that all variables in the state vector have unique steady-state values. Of course, whether this steady-state is stable or not depends on the precise feedback coefficients in the rule.
} 


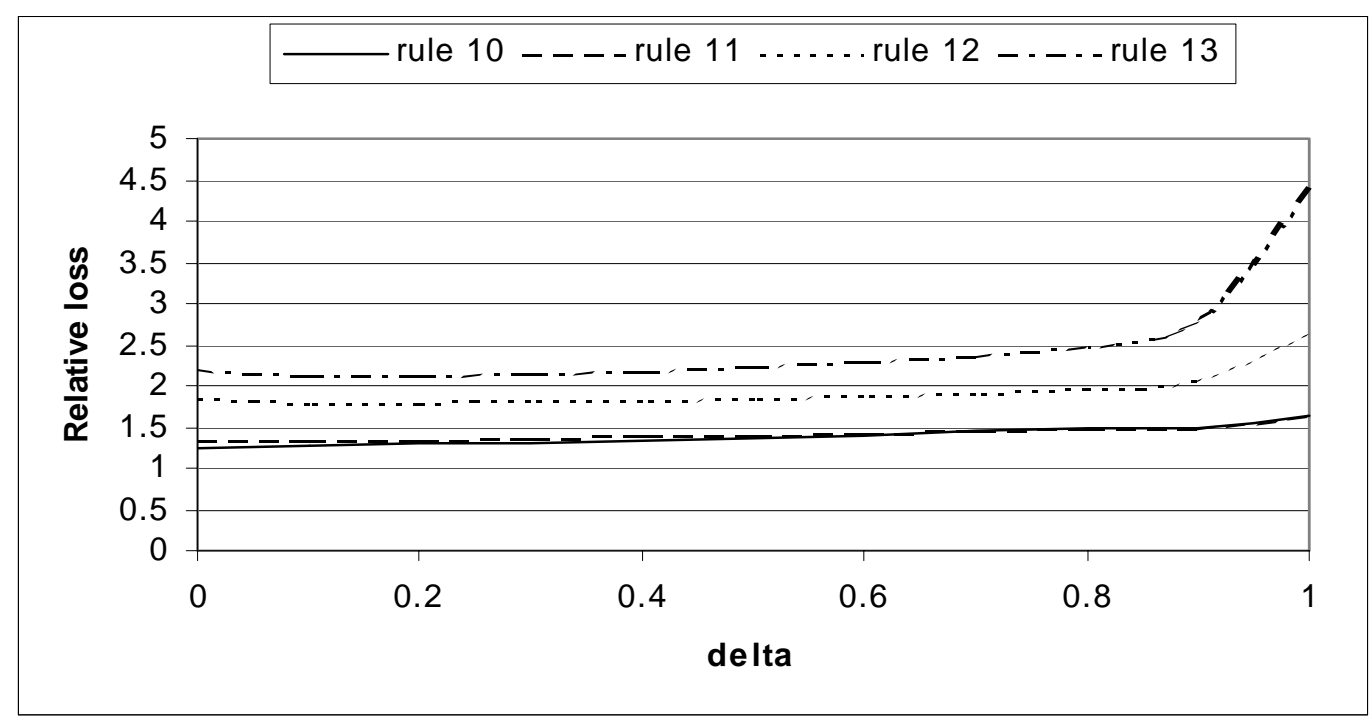

Figure 4: Relative loss for price level targeting rules

If policymakers use Rule 10 to set policy, then loss is raised between 30 per cent and 50 per cent depending on $\delta$. As $\delta$ rises, and policymakers place more weight on stabilizing the price level, the performance of each (optimal) simple rule declines relative to the optimal rule. Excluding the terms-of-trade from the rule (Rule 11) leads to only a very small increase in loss compared to Rule 10. Thus, with a price level target it appears relatively unimportant whether policymakers respond to the terms-of-trade or not. Interestingly, the percentage increase in loss from not responding to the terms-of-trade is greater for inflation targeting than it is for price level targeting.

By way of contrast, not responding to real exchange rate movements (Rule 12) leads to loss increasing more than 80 per cent for all $\delta$, and for loss more than doubling as $\delta$ approaches one. Thus, accounting for real exchange rate movements is considerably more important under price level targeting than it is under inflation targeting. Finally, not responding to either the real exchange rate or the terms-oftrade (Rule 13) represents a highly inefficient use of information.

In terms of volatility, Figure 5 shows the trade-off between the variances of inflation and the output gap under inflation and price level targeting. For this figure, it is assumed that policymakers make full use of all relevant information, i.e., policymakers consider all 14 state variables. 


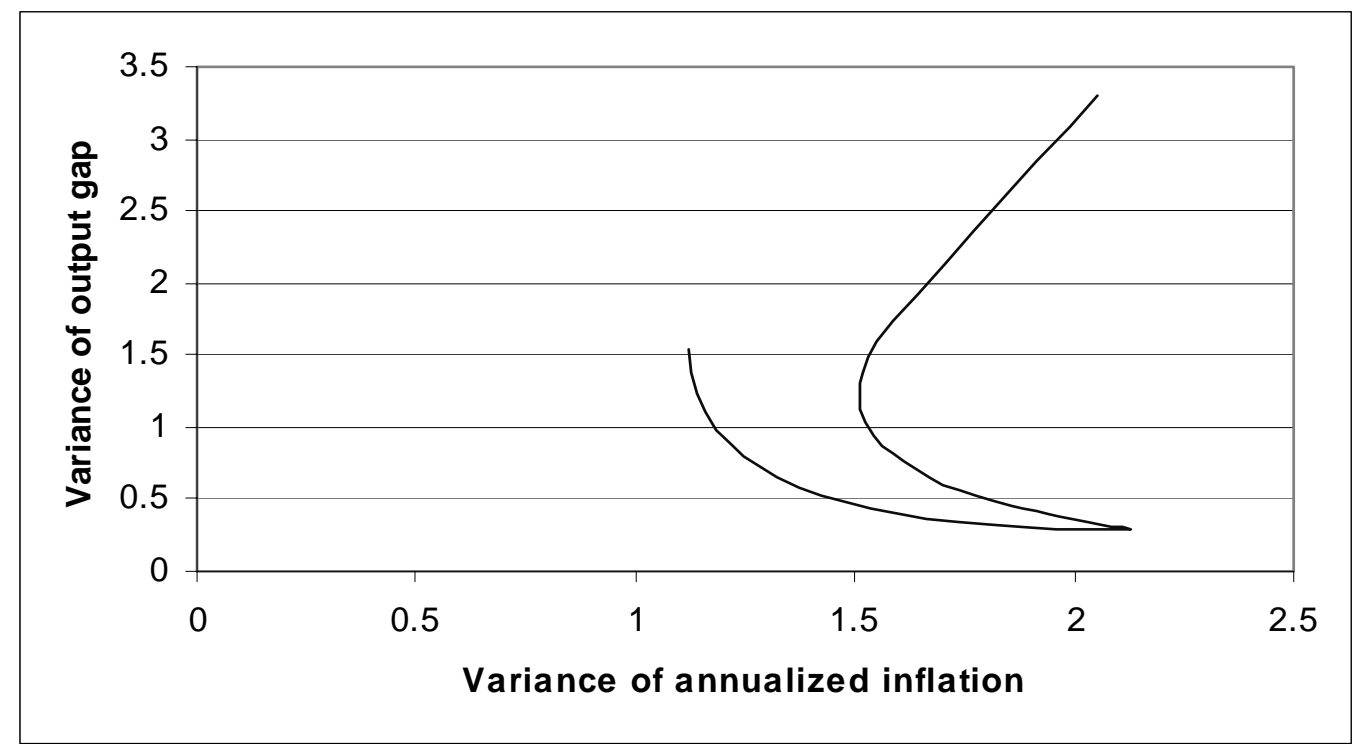

Figure 5: Variances under inflation and price level targeting

In Figure 5 the variance trade-off under inflation targeting is the curve closest to the origin. Both curves share the bottom-right most point, which corresponds to $\mu=\delta=0$. To construct these variance trade-offs we solve for the variances of the output gap and annualized inflation and then trace out how these variances change as $\mu$ and $\delta$ vary between 0 and 1 . The message from Figure 5 is that for a given variance of inflation, targeting the consumer price level generates considerably more output volatility than inflation targeting does. Delving deeper, Table 2 shows how volatility is distributed across variables under representative price level targeting and inflation targeting regimes.

\begin{tabular}{|c|c|c|c|c|c|c|c|c|c|}
\hline Table 2 & \multicolumn{9}{|c|}{ Unconditional Standard Deviations } \\
\hline & \multicolumn{4}{|c|}{ Price level targeting } & \multicolumn{4}{|c|}{ Inflation targeting } & \\
\hline & $4 \times \pi_{t}^{c}$ & $y_{t}$ & $q_{t}$ & $i_{t}$ & $4 \times \pi_{t}^{c}$ & $y_{t}$ & $q_{t}$ & $i_{t}$ & \\
\hline$\delta=0.3$ & 1.318 & 0.76 & 6.13 & 3.77 & 1.288 & 0.61 & 6.24 & 3.32 & $\mu=0.3$ \\
\hline$\delta=0.5$ & 1.270 & 0.87 & 5.94 & 4.11 & 1.192 & 0.73 & 6.01 & 3.66 & $\mu=0.5$ \\
\hline$\delta=0.7$ & 1.235 & 1.02 & 5.77 & 4.62 & 1.115 & 0.89 & 5.78 & 4.21 & $\mu=0.7$ \\
\hline & $l c_{t}-p_{t}^{c}$ & $p_{t}^{c}$ & & & $l c_{t}-p_{t}^{c}$ & $p_{t}^{c}$ & & & \\
\hline$\delta=0.3$ & 0.78 & 0.86 & & & 0.75 & $\infty$ & & & $\mu=0.3$ \\
\hline$\delta=0.5$ & 0.81 & 0.68 & & & 0.77 & $\infty$ & & & $\mu=0.5$ \\
\hline$\delta=0.7$ & 0.85 & 0.52 & & & 0.81 & $\infty$ & & & $\mu=0.7$ \\
\hline
\end{tabular}

Table 2 is not exhaustive, nor is it intended to be, however an interesting pattern does emerge. Price level targeting tends to produce greater volatility in consumer price inflation, the output gap, the nominal interest rate, and real unit labor costs 
than inflation targeting does. Greater volatility in real unit labor costs occurs because with a price level target eventually nominal wages have to do the adjusting needed to clear the labor market. Similarly, the higher interest rate volatility is brought about by the more aggressive interventions that are needed to restore the price level to its previous path following shocks. With an inflation target policymakers have less need to intervene because they can let "bygones-be-bygones."

On the plus side, price level targeting leads to less volatility in the real exchange rate because policymakers act to dampen nominal exchange rate movements in order to reduce import price volatility (import prices are expressed in domestic currency), which feeds directly into consumer prices. However, the key advantage to targeting the price level is not that it produces less volatility in inflation, output, interest rates, etc, (which it does not) but rather that it stabilizes the price level itself, making future prices much easier for agents to predict.

Motivated by these results, in our final experiment we merge inflation targeting and price level targeting through the objective function

$$
\text { Loss }=(1-\beta) \sum_{j=0}^{\infty} \beta^{j}\left[\mu\left(\pi_{t+j}^{c}\right)^{2}+(1-\mu) y_{t+j}^{2}+\delta\left(p_{t+j}^{c}\right)^{2}\right], \delta \geq 0,0 \leq \mu \leq 1 .
$$

When $\delta$ is small this objective function places inflation targeting objectives at the forefront, but also makes price level targeting a background issue. In the limit as $\delta \longrightarrow 0$ this objective function converges to an inflation targeting regime. Thus it is always possible to find a value for $\delta$ that replicates inflation targeting to any degree of accuracy. But, with some weight on price level stability this objective function makes the price level (trend) stationary, thereby raising its predictability.

\begin{tabular}{ccccccc}
\hline \hline Table 3 & \multicolumn{5}{c}{ Hybrid Targeting Regime } \\
\hline \hline Regime & $4 \times \pi_{t}^{c}$ & $y_{t}$ & $q_{t}$ & $i_{t}$ & $l c_{t}-p_{t}^{c}$ & $p_{t}^{c}$ \\
\hline$\mu=0.3, \delta=0.10$ & 1.255 & 0.73 & 6.07 & 3.66 & 0.76 & 1.02 \\
$\mu=0.5, \delta=0.10$ & 1.179 & 0.83 & 5.88 & 3.99 & 0.80 & 0.90 \\
$\mu=0.7, \delta=0.10$ & 1.119 & 0.97 & 5.71 & 4.50 & 0.84 & 0.79 \\
\hline$\mu=0.3, \delta=0.05$ & 1.265 & 0.69 & 6.12 & 3.56 & 0.77 & 1.19 \\
$\mu=0.5, \delta=0.05$ & 1.184 & 0.80 & 5.92 & 3.89 & 0.79 & 1.04 \\
$\mu=0.7, \delta=0.05$ & 1.118 & 0.95 & 5.73 & 4.41 & 0.83 & 0.91 \\
\hline \hline
\end{tabular}

In Table 3 we arbitrarily choose $\delta=0.10$ and $\delta=0.05$ : the results are intriguing. Relative to an inflation target, output becomes more volatile, but the variance of inflation tends to fall, as does the variance of the real exchange rate. Admittedly 
these differences are small. However, even with small weights on price level stability, the variance of the price level drops dramatically. Hence, large improvements in price level predictability can be achieved if policymakers act with merely a subsidiary concern for price level stability.

\section{Conclusions}

An issue currently being debated in the literature is whether policymakers in small open-economies should respond to exchange rate movements when setting monetary policy. Micro-founded sticky-price models of small open-economies have tended to find that there is little or nothing to be gained from such a response. Instead, the exchange rate's main effect in these models is to make domestic-good's consumption more sensitive to interest rate movements, strengthening the policy channel into aggregate demand. This result is surprising because it suggests that the policy formulation process in small open economies is essentially the same as that for large, or closed, economies.

This paper brings this debate to the Australian context, a context in which real exchange rate movements are often large. In section 2 two micro-founded sticky-price small open-economy models were analyzed. The main difference between these two models lay in how they treated imports. One model viewed imports as consumption goods; the other viewed them as intermediate inputs. These models suggest that a central bank that targets consumer price inflation would only want to respond to exchange rate movements to the extent that imports are consumption goods.

A small-scale macroeconomic model that has been developed within the RBA (de Brouwer and O'Regan, 1997) was introduced in section 3. The Bank uses this model for forecasting and optimal control exercises. Section 4.1 analyzed the de Brouwer and O'Regan model under the reasonable assumption that Australian monetary policy could be modeled as an inflation targeting regime. By systematically examining rules that alternatively included and excluded the real exchange rate and the terms-of-trade, section 4.1 showed that it was optimal for monetary policy to respond to both the exchange rate and the terms-of-trade, but especially to the real exchange rate. This finding is consistent with SVAR models of the Australian economy. Thus the de Brouwer and O'Regan model and Australian empirical evidence suggest not only that Australian monetary policy has responded to real exchange rate movements, but that it should. Reconciling this result with the micro-founded 
models in section 2, we showed that the de Brouwer and O'Regan model's treatment of imports was consistent with imports being consumption goods.

Section 4.2 examined forward-looking rules. Of interest here was whether rules that contain expectations of future inflation, but exclude the real exchange rate and the terms-of-trade, can closely approximate the optimal policy rule. We found that they could. In this respect our simulation results are consistent with Batini and Haldane (1999) and Batini, et al. (2001). However, it was also shown that this does not imply that policymakers do not respond to the real exchange rate or the terms-of-trade; both variables help agents form expectations of future inflation.

Section 4.3 investigated whether the results from section 4.1 were sensitive to price level targeting, and compared price level targeting with inflation targeting more generally. For price level targeting we found that responding to real exchange rate movements was even more important than it was for inflation targeting. However, once policymakers allowed for exchange rate movements it became relatively unimportant whether they also responded to the terms-of-trade. More generally, relative to inflation targeting, price level targeting tended to raise the variances of consumer price inflation, output, nominal interest rates, and real unit labor costs. But price level targeting reduced the variance of the real exchange rate and made the price level itself much easier to predict. The latter result, in particular, should facilitate better decision making by private agents. Finally, we showed that a targeting regime that coupled a focus on inflation targeting with a subsidiary concern for price level stability reaped most of the benefits of a price level target without creating large increases in volatility elsewhere in the economy.

\section{A Appendix - Model calibrations for section 2}

The parameter values for the simulations in section 2 are those used in Galí and Monacelli (2000) and McCallum and Nelson (2001). For convenience they are shown in Table A1. 


\begin{tabular}{|c|c|c|c|}
\hline Table A1 & \multicolumn{3}{|c|}{ Model Calibrations } \\
\hline \multicolumn{4}{|c|}{ "Galí and Monacelli model } \\
\hline$\beta=0.99$ & $\phi=1.00$ & \multirow{3}{*}{\multicolumn{2}{|c|}{$\begin{array}{c}\lambda=\theta^{-1}(1-\theta)(1-\beta \theta) \\
\omega=1+\alpha(\sigma \eta-1)(2-\alpha) \\
\rho=0.90\end{array}$}} \\
\hline$\alpha=0.40$ & $\eta=1.50$ & & \\
\hline$\theta=0.75$ & $\sigma=1.00$ & & \\
\hline \multicolumn{4}{|c|}{ McCallum and Nelson model } \\
\hline$\beta=0.99$ & $\omega_{1}=0.89$ & $\sigma^{*}=1.00$ & $\rho_{\xi}=0.50$ \\
\hline$b_{1}=0.20$ & $\omega_{2}=0.00$ & $\lambda=0.086$ & $\rho_{z}=0.95$ \\
\hline$\alpha=0.40$ & $\omega_{3}=0.11$ & & $\rho_{v}=0.30$ \\
\hline$\sigma=0.33$ & $\omega_{4}=0.00$ & & \\
\hline
\end{tabular}

\section{References}

[1] Backus, D., and J. Driffill, (1986), "The Consistency of Optimal Policy in Stochastic Rational Expectations Models," Centre for Economic Policy Research Discussion Paper \#124.

[2] Ball, L., (1999), "Policy Rules for Small Open Economies," in Taylor, J., (ed) Monetary Policy Rules, University of Chicago Press, Chicago.

[3] Batini, N., and A. Haldane, (1999), "Forward-Looking Rules for Monetary Policy," in Taylor, J., (ed) Monetary Policy Rules, University of Chicago Press, Chicago.

[4] Batini, N., Harrison, R., and S. Millard, (2001), "Monetary Policy Rules for an Open Economy," Norges Bank Working Paper \#2001-04.

[5] Beechey, M., Bharucha, N., Cagliarini, A., Gruen, D., and C. Thompson, (2000), "A Small Model of the Australian Macroeconomy," Reserve Bank of Australia Discussion Paper \#2000-05.

[6] Brischetto, A., and G. Voss, (1999), "A Structural Vector Autoregressive Model of Monetary Policy in Australia," Reserve Bank of Australia Discussion Paper \#1999-11.

[7] Calvo, G., (1983), "Staggered Prices in a Utility-Maximizing Framework," Journal of Monetary Economics, 12, 3, pp383-398.

[8] Clarida, R., Galí, J., and M. Gertler, (2001), "Optimal Monetary Policy in Open versus Closed Economies: An Integrated Approach," American Economic Review, 91, 2, pp248-252.

[9] Currie, D., and P. Levine, (1985), "Macroeconomic Policy Design in an Interdependent World," in Buiter, W., and R. Marston (eds) International Economic Policy Coordination, Cambridge University Press, Cambridge.

[10] Currie, D., and P. Levine, (1993), "The Design of Feedback Rules in Linear Stochastic Rational Expectations Models," Chapter four in Rules, Reputation, and Macroeconomic Policy, Cambridge University Press, Cambridge. 
[11] de Brouwer, G., and N. Ericsson, (1997), "Modeling Inflation in Australia," Journal of Business and Economic Statistics, 16, 4, pp433-449.

[12] de Brouwer, G., and J. O'Regan, (1997), "Evaluating Simple Monetary-Policy Rules for Australia," in Lowe, P. (ed) Monetary Policy and Inflation Targeting, Reserve Bank of Australia Conference Volume.

[13] Dennis, R., (2001), "Optimal Policy Rules in Rational Expectations Models: New Solution Algorithms," Federal Reserve Bank of San Francisco Working Paper \#2001-09.

[14] Dungey, M., and A. Pagan, (2000), "A Structural VAR Model of the Australian Economy," Economic Record, 76, 235, pp321-342.

[15] Galí, J., and T. Monacelli, (2000), "Optimal Monetary Policy and Exchange Rate Volatility in a Small Open Economy," Universitat Pompeu Fabra, mimeo (May, 2000, version).

[16] Hansen, L., and T. Sargent, (1980), "Formulating and Estimating Dynamic Linear Rational Expectations Models," Journal of Economic Dynamics and Control, $2, \mathrm{pp} 7-46$.

[17] Harding, D., and A. Pagan, (2002), "Dissecting the Cycle: A Methodological Investigation," Journal of Monetary Economics, 49, pp365-381.

[18] King, M., (1999), "Challenges for Monetary Policy: New and Old," in New Challenges for Monetary Policy a Symposium Sponsored by the Federal Reserve Bank of Kansas City.

[19] Leitemo, K., and U. Söderström, (2001), "Simple Monetary Policy Rules and Exchange Rate Uncertainty," Sveriges Riksbank Working Paper \#122 (June version).

[20] Levin, A., Wieland, V., and J. Williams, (1999), "Robustness of Simple Monetary Policy Rules under Model Uncertainty," in Taylor, J., (ed) Monetary Policy Rules, University of Chicago Press, Chicago.

[21] McCallum, B., and E. Nelson, (1999), "Nominal Income Targeting in an OpenEconomy Optimizing Model," Journal of Monetary Economics, 43, pp553-578.

[22] McCallum, B., and E. Nelson, (2001), "Monetary Policy for an Open Economy: An Alternative Framework with Optimizing Agents and Sticky Prices," National Bureau of Economic Research Working Paper \#8175.

[23] Macfarlane, I., (2000), "Recent Influences on the Exchange Rate," Reserve Bank of Australia Bulletin, December.

[24] Obstfeld, M., and K. Rogoff, (1996), Foundations of International Macroeconomics, MIT Press, Cambridge.

[25] Oudiz, G., and J. Sachs, (1985), "International Policy Coordination in Dynamic Macroeconomic Models," in Buiter, W., and R. Marston (eds) International Economic Policy Coordination, Cambridge University Press, Cambridge. 
[26] Parkin, M., and R. Bade, (1990), Macroeconomics and the Australian Economy, 2nd Edition, Allen and Unwin Press, Sydney.

[27] Rudebusch, G., and L. Svensson, (1999), "Policy Rules for Inflation Targeting," in Taylor, J., (ed) Monetary Policy Rules, University of Chicago Press, Chicago.

[28] Sargent, T., (1987), Dynamic Macroeconomic Theory, 2nd Edition, Harvard University Press, Cambridge, Massachusetts.

[29] Shuetrim, G., and C. Thompson, (1999), "The Implications of Uncertainty for Monetary Policy," Reserve Bank of Australia Discussion Paper \#1999-10.

[30] Söderlind, P., (1999), "Solution and Estimation of RE Macromodels with Optimal Policy," European Economic Review, 43, pp813-823.

[31] Stevens, G., (1998), "Pitfalls in the Use of Monetary Conditions Indexes," Reserve Bank of Australia Bulletin, August.

[32] Stevens, G., (1999), "Six Years of Inflation Targeting," Reserve Bank of Australia Bulletin, May.

[33] Stevens, G., (2001), "The Monetary Policy Process at the RBA," Reserve Bank of Australia Bulletin, October.

[34] Svensson, L., (1997), "Inflation Forecast Targeting: Implementing and Monitoring Inflation Targets," European Economic Review, 41, pp1111-1146.

[35] Svensson, L., (1999a), "Inflation Targeting as a Monetary Policy Rule," Journal of Monetary Economics, 43, 3, pp607-654.

[36] Svensson, L., (1999b), "How should Monetary Policy be Conducted in an Era of Price Stability?," in New Challenges for Monetary Policy a Symposium Sponsored by the Federal Reserve Bank of Kansas City.

[37] Svensson, L., (2000), "Open-Economy Inflation Targeting," Journal of International Economics, 50, 1, pp155-183.

[38] Taylor, J., (1993), "Discretion versus Policy Rules in Practice," CarnegieRochester Conference Series on Public Policy, 39, pp195-214.

[39] Taylor, J., (2001), "The Role of the Exchange Rate in Monetary-Policy Rules," American Economic Review, 91, 2, pp263-267. 